\title{
Use of metabolomics to the diagnosis of inflammatory bowel disease
}

\author{
Manoel Álvaro de Freitas LINS NETO, Giulia Maria Ximenes VERDI, Arthur de Oliveira VERAS, \\ Matheus de Oliveira VERAS, Luiz Carlos CAETANO and Jeferson Santana URSULINO
}

\begin{abstract}
Background - Crohn's disease and ulcerative colitis are the primary inflammatory bowel diseases (IBD), and its pathogenesis is related to genetic and environmental factors. Currently, the diagnosis of IBD results in a multidisciplinary approach with significant disadvantages, such as its invasive nature, time spent, and the fact that $10 \%$ of patients remain without diagnostic classification. However, new methodologies of analysis have emerged that allowed the expansion of knowledge about IBD, as the metabolomics, the study of metabolites. The presence and prevalence of such metabolites may prove to be useful as biomarkers in the diagnosis of IBD. Objective - Analyze fecal samples for metabolic analysis in the diagnosis of inflammatory bowel diseases (IBD), providing differentiation between Crohn's disease and ulcerative colitis. Methods - This is an observational study with 21 patients diagnosed with IBD (ulcerative colitis 11 and Crohn's disease 10) and 15 healthy controls, all with the consent and clarification. The fecal extracts of all patients are submitted to a high-resolution Nuclear Magnetic Resonance Hydrogen ( $\left.{ }^{1} \mathrm{H}-\mathrm{NMR}\right)$ spectroscopy combined with multivariate and univariate pattern recognition techniques. Through the metabolomics of fecal extracts, gives us a characterization of employing a noninvasive approach. Results - We identify some metabolites, such as lactate, succinate, alanine, and tyrosine, in the Crohn's disease fecal samples, and leucine, alanine, and tyrosine in the ulcerative colitis fecal samples. All the amino acids presented positive covariance for disease correlation. Conclusion - The results showed different metabolic profiles between IBD patients and healthy volunteers based on ${ }^{1} \mathrm{H}-\mathrm{NMR}$ analysis of fecal extracts. Moreover, the approach discriminated patients with Crohn's disease and ulcerative colitis. The metabolomics analysis is promising as a novel diagnostic technique for further IBD recognition and surveillance. New studies are necessary to validate these findings.
\end{abstract}

HEADINGS - Inflammatory bowel diseases. Crohn's disease. Proctocolitis. Biomarkers. Metabolomics.

\section{INTRODUCTION}

Inflammatory bowel disease (IBD) is a chronic gastrointestinal tract disorder due to its inflammation and epithelial lesions ${ }^{(1)}$ Crohn's disease (CD) and ulcerative colitis (UC) are significant IBD, and its etiology is still unknown. Despite all efforts to reach the diagnosis and to define a more individualized treatment for patients with $\mathrm{CD}$ and UC, following the ECCO-ESGAR Guideline for diagnostic assessment in inflammatory bowel disease, a single standard as reference for the diagnosis of $\mathrm{CD}$ or $\mathrm{UC}$ until now does not exist ${ }^{(2,3)}$. Genetic and environmental factors are believed to be involved in its pathogenesis ${ }^{(4)}$. Also, there is evidence that IBD is related to intestinal microbiota dysbiosis ${ }^{(5)}$.

Currently, in the absence of trustful evidence to support the best modality to assess these diseases, IBD diagnosis is based on a multidisciplinary approach which involves clinical history, endoscopy, radiology, histology, microbiology, and hematology ${ }^{(6)}$. Colonoscopy is currently used as the gold standard diagnostic method for the evaluation and monitoring of IBD. This process has the following drawbacks: its invasive nature, and $10 \%$ to $15 \%$ of the patients remain without diagnostic classification ${ }^{(6)}$. Technologies such as metabolomics and metagenomic have emerged in the last decade, offering alternatives for identification and differentiation of inflammatory bowel diseases. Such technologies are more effective and less invasive, and they open new perspectives in the diagnosis of this class of disease.

The use of metabolomics is an emerging approach for analyzing the physiology and cellular pathophysiology through the identification of metabolic profiles ${ }^{(7)}$. Metabolomics is in the group of omics (transcriptomics, genomics, and proteomics), related to investigations of biochemical profiles, defined as an analysis of macromolecules (metabolites) produced by the metabolism of an organism, organ or living tissue, considering the genetic expression under the influence of disease, lifestyle, and environmental factors. The metabolomics analysis monitors the metabolic state enabling the understanding of complex biological interactions, and defines biomarkers related to specific conditions; in our study, $\operatorname{IBDs}^{(8-12)}$.

Preliminary studies reveal that metabolomics can differentiate between individuals with IBD and control groups, as well as between the IBD subtypes, using, for example, metabolic profiles of fecal extracts ${ }^{(8)}$. Metabolomics is still an under-explored approach to identify biomarkers in fecal samples of patients with IBD, and can be potentially used for disease surveillance ${ }^{(9)}$. In this sense, several markers have been proposed to assess the disease activity ${ }^{(10)}$.

Declared conflict of interest of all authors: none

Disclosure of funding: Universidade Federal de Alagoas.

Research performed at: Coloproctology Department of Hospital Universitário Professor Alberto Antunes, Maceió, AL, Brasil.

Universidade Federal de Alagoas, Maceió, AL, Brasil.

Corresponding author: Manoel Álvaro de Freitas Lins Neto. E-mail: mlinsneto@gmail.com 
Among the tools that have good performance for the study of metabolomics, the High-Resolution Nuclear Magnetic Resonance Hydrogen $\left({ }^{1} \mathrm{H}-\mathrm{NMR}\right)$ stands out ${ }^{(11,12)}$. This methodology is attractive due to the simplicity involved in the sample preparation and for its ability to discover the chemical identities of unknown peaks in the formed spectra. ${ }^{1} \mathrm{H}-\mathrm{NMR}$ spectroscopy of fecal samples, tissue, and urine successfully distinguishes patients with $\mathrm{CD}$ and UC from healthy individuals ${ }^{(9,13,14)}$.

This study investigates the potential of ${ }^{1} \mathrm{H}-\mathrm{NMR}$ spectroscopy in the identification of metabolites presented in fecal samples of individuals with IBD. We verify the differences between the metabolic expression profile of healthy patients from those with CD and UC. The focus is on the definition and differentiation of potential biomarkers in the diagnosis of inflammatory bowel diseases through the metabolomics analysis of fecal samples.

\section{METHODS}

This was an observational and transversal study. The work was approved by the Ethics Committee of the Federal University of Alagoas (CAAE: 55813816.2.0000.5013). We use an ${ }^{1} \mathrm{H}-\mathrm{NMR}$ spectrometer to analyze the stool samples from 36 individuals: CD ( $\mathrm{n}=10,6$ males, 4 females, and age between 25 and 60 years), UC $(n=11,8$ females, 3 males, age between 25 and 70 years) and healthy controls, $\mathrm{HC}(\mathrm{n}=15,9$ females, 6 males, age between 30 and 79 years, without a history of any pathology in the gastrointestinal tract).

Fecal specimen collection and preparation (FIGURE 1): First, the fecal samples are collected and, immediately, begins the process obtaining fecal water. The sample is added to the mortar, and the mixture is crushed with distilled water and liquid nitrogen. Next, the samples in Eppendorf are centrifuged and the supernatant is collected and stored for ${ }^{1} \mathrm{H}-\mathrm{NMR}$ analysis.

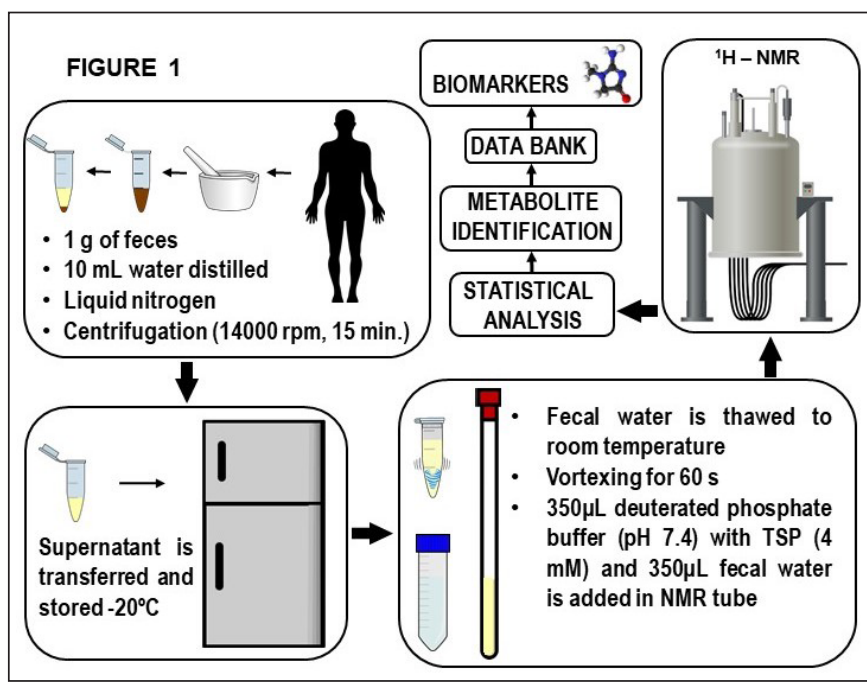

FIGURE 1. Material and methods for the preparation of fecal water and analyzed by ${ }^{1} \mathrm{H}-\mathrm{NMR}$.

Fecal water analysis by ${ }^{1} \mathrm{H}-\mathrm{NMR}$ spectrometry: The fecal water is thawed to ambient temperature and is homogenized in vortexing for $60 \mathrm{~s}$. Then, the sample is transferred to the ${ }^{1} \mathrm{H}-\mathrm{NMR}$ tube, to add the solution deuterated phosphate buffer $(\mathrm{pH}=7.4)$ with TSP (3-trimethylsilyl-2, 2, 3, 3-tetradeuteriumpropionate) in ${ }^{1} \mathrm{H}-\mathrm{NMR}$ tubes for analysis.
Obtaining the ${ }^{1} \mathrm{H}-\mathrm{NMR}$ spectra: All ${ }^{1} \mathrm{H}-\mathrm{NMR}$ experiments were performed at $298.15 \mathrm{~K}$ (Kelvin) using a Bruker $400 \mathrm{MHz}$ spectrometer (Bruker Biospin). The spectra were acquired with $64 \mathrm{~K}$ dots, 128 transients (scans) with the spectral width of 10.5 parts per million (ppm) and suppression of the water signal, using the pulses sequence noesyprld, with 2 seconds (s) of relaxation time, 100 milliseconds (ms) of mixing time. The results were processed in the TOPSPIN (V 3.5, Bruker Biospin) program. The chemical shifts $(\delta)$ were calibrated concerning the signal of TSP at $0.0 \mathrm{ppm}$, and were manually corrected for phase and baseline distortions.

\section{Data analysis}

Despite the suppression of the water signal, we removed the water of region $\delta 5.00-4.70 \mathrm{ppm}$ from all spectra. The ${ }^{1} \mathrm{H}-\mathrm{NMR}$ spectra data set were normalized by the median, compensating the differences in sample concentration, using MetaboAnalyst 4.0. We applied Partial Least Squares Discriminant Analysis (PLS-DA) to the ${ }^{1} \mathrm{H}-\mathrm{NMR}$ spectral data set to facilitate the interpretation, discriminating against the of fecal biochemical profiles of each group. We identified the metabolites responsible for the difference between UC and CD, and between HC and UC by the Variance Analysis of Cross-Validated Residues CV-ANOVA; we set the $P$-value threshold at 0.05 to verify the validity of the models ${ }^{(15)}$. The model is considered valid when the permutation test and the CV-ANOVA test are satisfied at the same time.

\section{RESULTS}

\section{Investigation of the ${ }^{1} \mathrm{H}-\mathrm{NMR}$}

The ${ }^{1} \mathrm{H}-\mathrm{NMR}$ spectra came from all the 36 patients (diagnosticated with $\mathrm{CD}, \mathrm{UC}$, and the $\mathrm{HC}$ ). The area referring to the aromatic hydrogen signals, $\delta 6.0$ to 9.0 , was insufficient to identify the cues and to distinguish each one of them since the signals were of low intensity. Also, it was not possible to visually perceive a pattern of differences between the spectra of the two data sets (HC versus $\mathrm{UC}$, and $\mathrm{HC}$ versus $\mathrm{CD}$ ). Therefore, the use of features such as chemometrics to identify the signals became necessary.

\section{Identification of the signals in the ${ }^{1} \mathrm{H}-\mathrm{NMR}$ spectra}

The signals were attributed to compounds belonging to different classes, such as short chain fatty acids (SCFA), aminoacids, other organic acids intermediate of Krebs cycle, amines, and nucleotides. TABLE 1 shows the assignment of the signals. The identification of the metabolites was possible by comparing with the data in the Human Metabolome Database (available at hmdb.ca) and with the use of CHENOMXTM (evaluation mode).

The metabolites found are in agreement with the literature. The intermediates of the Krebs cycle and SCFA are possible metabolites in fecal samples ${ }^{(16)}$, as well as the metabolites such as butyrate, propionate, and lactate ${ }^{(9)}$. FIGURE 2 shows the metabolites identified in TABLE 1. Due to the complexity of the spectra, some signals not yet were found.

\section{Analysis with PLS-DA and CV-ANOVA (P-value <0.05)}

The ANOVA helped reduce the possibly large number of metabolites investigated, keeping only those that showed the most reliable response under the conditions studied, to discriminate against the groups ${ }^{(15)}$. 
TABLE 1. Chemical displacement of identified metabolites.

\begin{tabular}{lcc}
\hline Molecular name & Chemical displacement & Multiplicity \\
\hline Acetate & 1.92 & Singlet \\
Alanine & 1.48 & Doublet \\
Butyrate & 0.90 & Triplet \\
Butyrate & 1.56 & Doublet \\
Butyrate & 2.16 & Triplet \\
Choline & 3.21 & Singlet \\
Creatinine & 3.05 & Singlet \\
Ethanol & 1.19 & Triplet \\
Ethanol & 3.66 & Quartet \\
Formate & 8.46 & Singlet \\
Glutamate & 2.36 & Doublet of Triplet \\
Glycine & 3.56 & Singlet \\
Hypoxanthine & 8.2 & Doublet \\
Lactate & 1.33 & Doublet \\
Lactate & 4.12 & Quartet \\
Leucine & 0.96 & Triplet \\
Leucine & 1.71 & Multiplet \\
Leucine & 3.73 & Triplet \\
Lysine & 3.03 & Triplet \\
Methanol & 3.36 & Singlet \\
Propionate & 1.06 & Triplet \\
Phenylalanine & 7.39 & Multiplet \\
Succinate & 2.41 & Singlet \\
TMAO & 3.27 & Singlet \\
Tyrosine & 6.91 & Doublet \\
Tyrosine & 7.2 & Doublet \\
Trimethylamine & 2.89 & Singlet \\
Tryptophan & 7.55 & Doublet \\
Tryptophan & 7.74 & Doublet \\
\hline & & \\
& &
\end{tabular}

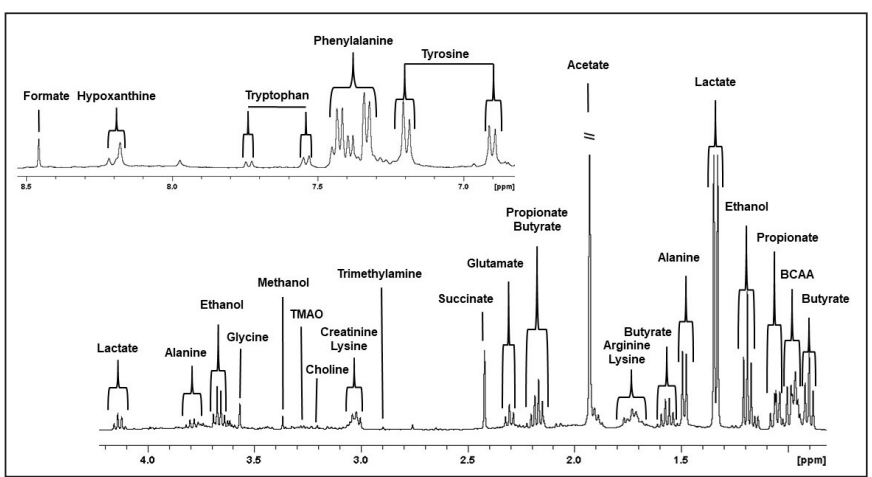

FIGURE 2. Spectrum ${ }^{1} \mathrm{H}-\mathrm{NMR} 400 \mathrm{MHz}$ of the fecal water samples.

\section{Healthy controls $x$ Crohn disease}

The results of PLS-DA between the HC and CD groups (FIGURE 3) showed that the groups are well defined and demonstrate a significant difference in Metabolism. Component \# 2 (the variance between spectra ${ }^{1} \mathrm{H}-\mathrm{NMR}$ in the same group) was $22.6 \%$, and Component \# 1 (the variance between the sets generated by $\mathrm{HC}$ and $\mathrm{CD}^{1} \mathrm{H}-\mathrm{NMR}$ spectra), was $40.02 \%$.

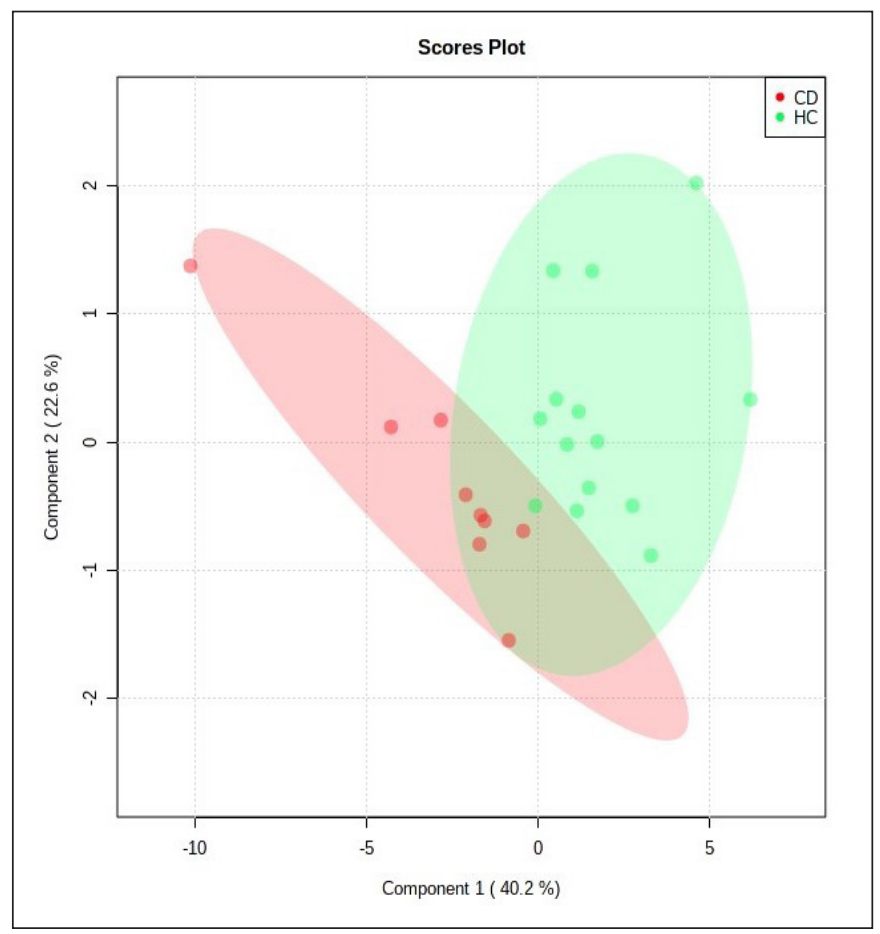

FIGURE 3. Fingerprint of fecal metabolomic profiles analyzed by ${ }^{1} \mathrm{H}-\mathrm{NMR}$. HC vs CD. PLS-DA plot of water fecal obtained from healthy controls (green dots) and CD patients (red dots). Component 1, 40.2\% and component $2,22.6 \%$.

The results were validated through Cross-Validation, with an accuracy of $100.0 \%$. Both samples, HC and CD, were well classified, showing $100 \%$ of classification. The distinction between these profiles has already been observed in previous studies using the same methodology $y^{(9)}$.

Through ANOVA, it was possible to identify which metabolites discriminate against the $\mathrm{HC}$ and the $\mathrm{CD}$ samples. Lactate $(\delta 1.33$ $P=0.0050338)$, succinate $(\delta 2.41 P=0.0020639)$, alanine $(P=0.001)$ and tyrosine $(P=0.002)$ presented a positive covariance for Crohn's disease, with a strong correlation for disease discrimination. An important data was the sign of ethanol ( $\delta 1.19 P=0.00011198$ ) with positive covariance for the $\mathrm{HC}$ samples, which presented such a greater quantity to discriminate $\mathrm{CD}$.

\section{Healthy controls $(\mathrm{HC}) \times$ ulcerative colitis (UC)}

The PLS-DA applied to data set HC x UC (FIGURE 4) showed homogeneity among the ${ }^{1} \mathrm{H}-\mathrm{NMR}$ spectra of the same group, with the value of component \#2 of $9.9 \%$, despite component \#1 with $26.1 \%$ presenting a significant variance. This finding has already reported in previous studies using the same methodology ${ }^{(15)}$.

The Cross-Validation test resulted in $69 \%$ of precision. That is, from a total of $11 \mathrm{UC}$ samples, $6(54.5 \%)$ were well classified and $5(45.5 \%)$ presented similarity to the HC. Among the 15 samples diagnosed as $\mathrm{HC}, 12(80.0 \%)$ were classified as $\mathrm{HC}$, and $3(20.0 \%)$ were not grouped in any class.

By ANOVA $(P<0.05)$ the discriminant metabolites of UC comparing with $\mathrm{HC}$, were leucine $(\delta 0.96 P=0.0001)$, alanine $(\delta 1.48$ $P=0.008)$, and tyrosine $(\delta 6.69 P=0.003)$. All three amino acids presented positive covariance in disease correlation. Again, the ethanol ( $\delta$ 1.19) discriminated against the $\mathrm{HC}$ samples. 


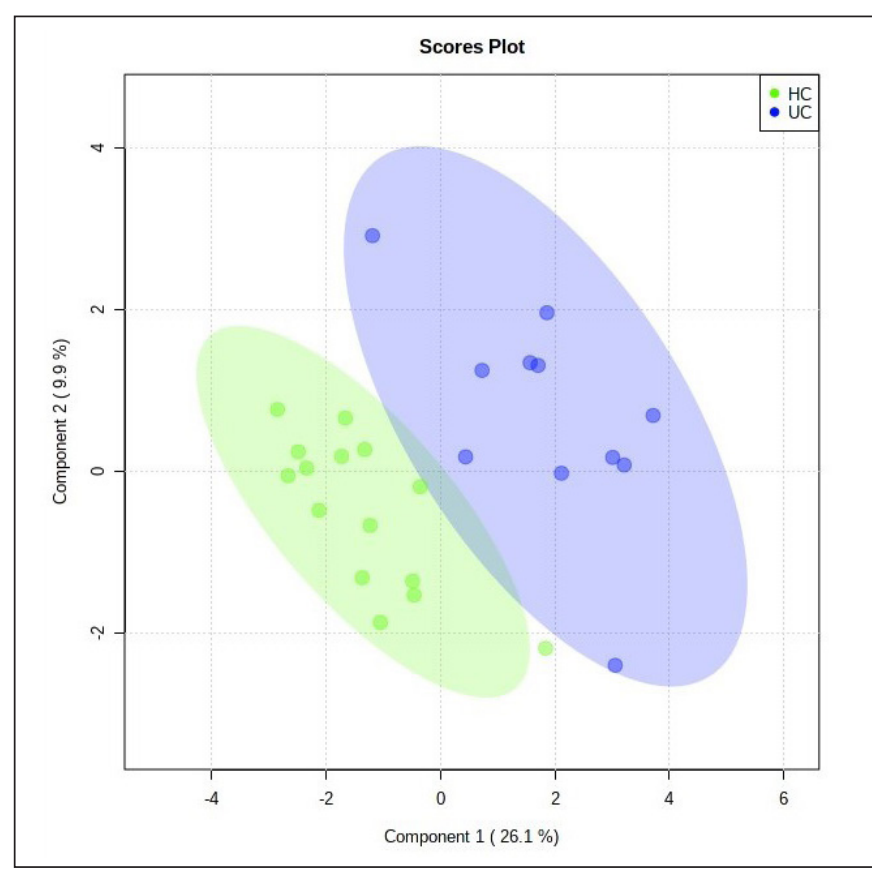

FIGURE 4. Fingerprint of fecal metabolomic profiles analyzed by ${ }^{1}$ H-NMR. HC vs UC. PLS-DA plot of water fecal obtained from healthy controls (green dots) and UC patients (blue dots). Component 1, 26.1\% and component $2,9.9 \%$.

\section{DISCUSSION}

This study focuses on the use of ${ }^{1} \mathrm{H}-\mathrm{NMR}$ spectrometry in the diagnosis of inflammatory bowel disease. Several studies have shown that ${ }^{1} \mathrm{H}-\mathrm{NMR}$ metabolomics is promising. Patients with identical clinical evaluation and diagnosed with IBD may have different outcomes. In addition, the metabolites found in IBD when compared to the $\mathrm{HC}$ group, show changes that may imply response and/or resistance to therapy. Through the metabolomics it was not possible to discriminate the final products of the fermentation of SCFA (butyrate, propionate), having identified the increase of the intermediate compounds, suggesting a dysbiosis of the intestinal microbiota. The increase of intermediate metabolites, including lactate and succinate, appears as a prominent feature in $\mathrm{CD}$ patients if compared with healthy subjects. Studies suggest that the rise of such metabolites is due to a dysbiosis of the host intestinal microbiota $^{(4,8)}$. Bacteria of the genus Phascolarctobacterium behaves as exclusive consumers of succinate and propionate when associated with bacteria of the genus Paraprevotella ${ }^{(17)}$. Thus, the decrease of Phascolarctobacterium bacteria in IBD may reflect in a reduction in propionate production ${ }^{(17)}$. Studies also showed that propionate is formed from pyruvate, by decarboxylation of succinate or via the acrylate pathway, where lactate is reduced to propionate ${ }^{(18)}$. Thus, with the reduction of the succinate-consuming bacteria and the propionate-producing bacteria, the intermediate compounds of succinate and lactate raise considerably.

Several culture-independent analyses of the diversity of microbiota associated with IBD have shown that the groups Clostridium coccoides and C. leptum decrease when compared to healthy subjects $^{(9,19)}$. These bacterial groups are functionally important, as they are primarily responsible for the production of SCFA, which provides energy to intestinal cells and promotes epithelial growth ${ }^{(9)}$. This dysbiosis may occur due to the destruction of microbiota by the Tlymphocytes, which are hyperactive against bacterial antigens and promote inflammatory destruction of the epithelial cells, which could lead to malabsorption of nutrients ${ }^{(9,20)}$. We found increased amounts of amino acids, including alanine, tyrosine, and leucine, in the feces of patients with $\mathrm{CD}$ and UC when compared to the HC. This effect may be the consequence of malabsorption caused by the inflammation.

After analyzing the data with the PLS-DA statistical methodology, the results showed that the metabolic analyses of fecal water by ${ }^{1} \mathrm{H}-\mathrm{NMR}$ spectrometry were useful in differentiating the patients with inflammatory bowel disease from healthy individuals. Although CD and UC share many epidemiological, immunological, therapeutic, and clinical characteristics, the results of metabolomics also have shown the formation of two distinct subtypes of IBD. The changes in metabolic profiles observed from UC subjects were not as marked as those observed with the $\mathrm{CD}$ group. It suggests that the metabolic consequences caused by inflammation are more severe in the CD group than in the UC group.

The literature reports distinctions between metabolic profiles within the disease, depending on the target affected ${ }^{(8-10,13)}$. In individuals with $\mathrm{CD}$, the studies have shown that the patterns affecting mainly ileum (CDI) and patterns primarily affecting the colon (CDC) are quite distinct. However, the CDC profile is similar to the profile of $\mathrm{HC}$, and there is no such significant difference between $\mathrm{HC}$ and $\mathrm{CDC}^{(8)}$. Our study distinguishes through metabolomics, the metabolic profile among $\mathrm{UC}, \mathrm{CD}$, and $\mathrm{HC}$. Therefore, the distinction of metabolomics in the disease at its different stages and locations is a promising future research in the metabolomics analysis of fecal samples of patients with inflammatory bowel disease.

Despite the small of the sample in this study, it was possible to infer that based on the results and responding to our objective, metabolomics is a valuable tool for investigation and determination of the distinction between Crohn's disease and ulcerative colitis. This alternative proved to be exciting and corroborates our results with those found in the literature.

\section{CONCLUSION}

It was possible to differentiate between IBD patients and healthy volunteers with ${ }^{1} \mathrm{H}-\mathrm{NMR}$ metabolic profiles of fecal extracts. Our study identified patients with CD and UC using this approach. Metabolomics has shown promising as a novel and a noninvasive diagnostic technique for further disease recognition and surveillance. Ongoing studies are necessary to validate these findings.

\section{ACKNOWLEDGEMENTS}

The authors are thankful to the Brazilian Ministry of Health for partial financial support. The authors also thank the Chemical Department and Medical School of Federal University of Alagoas 
(UFAL), for support in the analysis of the fecal samples, and the Institute of Multidisciplinary Skills in Intestinal Microbiota of UFAL, for collecting and storing the fecal samples.

\section{Authors' contribution}

Lins Neto MAF: lead research and article author. Verdi GMX, Veras AO, Veras MO: survey execution, data collection, writing of the text. Caetano LC, Ursulino JS: analysis of ${ }^{1} \mathrm{H}-\mathrm{NMR}$, statistical analysis, writing of the text.

\section{Orcid}

Manoel Álvaro de Freitas Lins Neto: 0000-0003-1903-844X.

Giulia Maria Ximenes Verdi: 0000-0002-6594-1982.

Arthur de Oliveira Veras: 0000-0001-8865-177X.

Matheus de Oliveira Veras: 0000-0001-9881-9855.

Luiz Carlos Caetano: 0000-0002-2415-0199.

Jeferson Santana Ursulino: 0000-0002-6292-4546.

Lins Neto MAF, Verdi GMX, Veras AO, Veras MO, Caetano LC, Ursulino JS. Uso da metabolômica no diagnóstico de doenças inflamatórias intestinais. Arq Gastroenterol. 2020;57(3):311-5.

RESUMO - Contexto - A doença de Crohn e retocolite ulcerativa são as principais doenças inflamatórias intestinais (DII), e sua patogênese está relacionada a fatores genéticos e ambientais. Atualmente, o diagnóstico de DII resulta em uma abordagem multidisciplinar e apresenta desvantagens significativas, como sua natureza invasiva, tempo gasto e o fato de $10 \%$ dos pacientes permanecerem sem classificação diagnóstica. No entanto, surgiram novas metodologias de análise que permitiram ampliar o conhecimento sobre a DII, como a metabolômica, o estudo dos metabólitos. A presença e a prevalência desses metabólitos podem ser úteis como biomarcadores no diagnóstico da DII. Objetivo - Avaliar as amostras fecais por análise metabolômica no diagnóstico de DII, diferenciando os perfis metabólicos entre doença de Crohn e retocolite ulcerativa. Métodos - Estudo observacional com 36 indivíduos (doença de Crohn 11, retocolite ulcerativa 10 e 15 controles saudáveis), todos com consentimento esclarecido. Os extratos fecais de todos os pacientes são submetidos a uma espectroscopia de alta resolução por ressonância magnética nuclear de hidrogênio $\left({ }^{1} \mathrm{H}-\mathrm{RMN}\right)$ combinada com técnicas de reconhecimento de padrões multivariados e univariados. Por meio da metabolômica utilizando extratos fecais, foi possível obter uma caracterização adequada das doenças inflamatórias intestinais através de uma abordagem não invasiva. Resultados - Foi possível identificar os seguintes metabólitos nos pacientes com doença de Crohn: lactato, succinato, alanina e tirosina e, no grupo retocolite ulcerativa encontrou-se leucina, alanina e tirosina. Todos os aminoácidos apresentaram covariância positiva para a doença. Conclusão-Os resultados demonstraram diferentes perfis metabólicos entre pacientes com DII e voluntários saudáveis, com base na análise por ${ }^{1} \mathrm{H}-\mathrm{RMN}$ dos extratos fecais. Além disso, pacientes com doença de Crohn e retocolite ulcerativa também podem ser discriminados usando essa abordagem. A análise metabolômica é promissora como uma nova técnica não invasiva de diagnóstico para melhor reconhecimento das DII. Novos estudos são necessários para validar esses achados.

DESCRITORES - Doenças inflamatórias intestinais. Doença de Crohn. Proctocolite. Biomarcadores. Metabolômica.

\section{REFERENCES}

1. Lee J, Park EJ, Youki Y, Ahmad S, Mizuguchi K, Ishii KJ, et al. Profiles of microRNA networks in intestinal epithelial cells in a mouse model of colitis. Sci Rep. 2015;5:18174.

2. Maaser C, Sturm A, Vavricka SR, Kucharzik T, Fiorino G, Annese V, et al. ECCO-ESGAR Guideline for Diagnostic Assessment in IBD Part 1: Initial diagnosis, monitoring of known IBD, detection of complications. J Crohns Colitis. 2019;13:144-64.

3. Sturm A. Maaser C, Calabrese E, Annese V, Fiorino G, Kucharzik T, et al ECCO-ESGAR Guideline for Diagnostic Assessment in IBD part 2: IBD scores and general principles and technical aspects. European Crohn's and Colitis Organisation (ECCO). 273 J Crohns Colitis. 2019;13:273-84.

4. Sartor RB. Mechanisms of disease: Pathogenesis of Crohn's disease and ulcerative colitis. Nature Clin Practice Nat Clin Pract Gastroenterol Hepatol. 2006;3:390-407.

5. Nishida A, Inoue R, Inatomi O, Bamba S, Naito Y, Andoh A. Gut microbiota in the pathogenesis of inflammatory bowel disease. Clin J Gastroenterol. 2018;11:1-10.

6. Geboes K, Colombel JF, Greenstein A, Jewell DP, Sandborn WJ, Vatn MH, et al. Indeterminate colitis: A review of the concept -- What is in a name? Inflamm Bowel Dis. 2008; 14:850-7.

7. Roda G, Caponi A, Sartini A, Cevenini M, Colliva C, Roda A. Update on curren applications of proteomics in the study of inflammatory bowel disease. Ann Gastroenterol. 2012;25:303-8.

8. Jansson J, Willing B, Lucio M, Fekete A, Dicksved J, Halfvarson J, et al. Metabolomics Reveal Metabolic Biomarkers of Crohn's Disease. PLoS One. 2009;4:1-10.

9. Marchesi JR, Holmes E, Khan F, Kochhar S, Scanlan P, Shanahan F, et al. Rapid and noninvasive metabonomic characterization of inflammatory bowel disease. J Proteome Res. 2007;6:546-51.

10. Fengming Y, Jianbing W. Biomarkers of inflammatory bowel disease. Dis Markers. 2014;2014:1-11.

11. Lindon JC, Nicholson JK. Analytical technologies for metabonomics and metabolomics, and multi-omic information recovery. Anal Chem. 2008;27:194-204.
12. Nicholson JK, Lindon JC. Systems biology: Metabonomics. Nature. 2008;455:1054-6.

13. Balasubramanian K, Kumar S, Singh RR, Sharma U, Ahuja V, Makharia GK, et al. Metabolism of the colonic mucosa in patients with inflammatory bowel diseases: an in vitro proton magnetic resonance spectroscopy study. Magn Reson Imaging. 2009;27:79-86.

14. Williams HRT, Cox IJ, Walker DG, North BV, Patel VM, Marshall SE, et al. Characterization of Inflammatory Bowel Disease With Urinary Metabolic Profiling. Am J Gastroenterol. 2009;104:1435-44.

15. Eriksson L, Trygg J, Wold S. CV-ANOVA for significance testing of PLS and OPLS $\AA$ models. J Chemom. 2008;22:594-600.

16. Smirnov, KS, Maier TV, Walker A, Heinzmann SS, Forcisi S, Martinez I, et al. Challenges of metabolomics in human gut microbiota research. Int J Med Microbiol. 2016;306:266-79.

17. Morgan XC, Tickle TL, Sokol H, Gevers D, Devaney KL, Ward DV, et al. Dysfunction of the intestinal microbiome in inflammatory bowel disease and treatment. Genome Biol. 2012;13:1-18.

18. Den Besten G, Van Eunen K, Groen AK, Venema K, Reijngoud DJ, Bakker BM. The role of short-chain fatty acids in the interplay between diet, gut microbiota, and host energy metabolism. J Lipid Res. 2013;54:2325-40.

19. Prosberg M, Bendtsen F, Vind I, Petersen AM, Gluud LL. The association between the gut microbiota and the inflammatory bowel disease activity: a systematic review and meta-analysis. Scand J Gastroenterol. 2016;51:1407-15.

20. Linskens RK, Huijsdens XW, Savelkoul PHM, Vandenbroucke-Grauls CM, Meuwissen SG. The Bacterial Flora in Inflammatory Bowel Disease: Current Insights in Pathogenesis and the Influence of Antibiotics and Probiotics. Scand J Gastroenterol. 2001;36:29-40. 